\title{
MOVIMIENTO, CUERPO Y GOBIERNO. Una mirada política sobre las danzas en el periodo tardo-colonial hispanoamericano, (Buenos Aires, siglo XVIII)
}

Bettina SIDY

CONICET, IDEAS-UBA (Argentina)

bettinasidy@gmail.com

MOVEMENT, BODY AND GOVERNMENT. A political view on the dances in the late-colonial SpanishAmerican period (Buenos Aires, eighteenth century)

Resumen: En el Buenos Aires colonial las festividades se constituyeron como los espacios claves para el despliegue de una variedad de factores sociales y políticos. En este trabajo analizaremos el desarrollo de dos formas, prototípicas y antagónicas, de baile festivo. Nos interesa reflexionar en torno a las formas en que se pretendió administrar el esparcimiento de la población, así como las valoraciones esgrimidas en cada instancia. Para ello, proponemos una mirada respecto a las valoraciones y las intenciones a partir de los cuales las elites gobernantes de la ciudad buscaron intervenir o incluso apropiarse de diversas formas festivas y expresiones populares de la sociedad porteña en el periodo tardo colonial. Asir el desborde carnavalesco, a la multitud y a sus efusiones. Crear un modelo de conducta apto y otro censurable y practicar el ejemplo. No obstante, las políticas culturales borbónicas se vieron severamente contestadas, ya fuera por el poder eclesiástico como por las propias lógicas sociales que atravesaban a la sociedad en sus gustos, prácticas, deseos y necesidades. En este sentido, la pretensión por modelizar la experiencia de ocio quedó restringida por las encrucijadas propias, de la política, la sociedad y la experiencia del periodo tardo colonial hispanoamericano.

Abstract: In colonial Buenos Aires, festivities were key areas for the deployment of a set of social and political factors. In this work we will analyze the development of two forms, prototypical and antagonistic, of festive dance. We will reflect on the ways in which it was intended to manage the recreation of the population, as well as the assessments used in each instance. We will review the purposes from which the ruling elites of the city sought to intervene or even appropriate various festive forms and popular expressions of Buenos Aires society in the late colonial period. Take over the carnival outburst, the crowd and their effusions. Divide between a fit and reprehensible behavior model and practice the example. However, Bourbon cultural policies were severely contested, either by ecclesiastical power or by the very social logics that permeated society in its tastes, practices, desires and needs. Thus, the pretension to model the leisure experience was restricted by its own crossroads, politics, society and the experience of the Late Latin American colonial period.

Palabras clave: Buenos Aires. Siglo XVIII. Reformismo borbónico. Bailes de máscaras. Tambos Buenos Aires. Eighteenth century. Bourbon Reformism. Masquerade balls. Tambos 


\section{Introducción}

En la Hispanoamérica colonial las festividades se constituyeron como los espacios claves para el despliegue de una variedad de factores sociales y políticos fundamentalmente en los contextos urbanos. El calendario religioso marcaba diversas festividades a lo largo del año y en ellas se practicaron juegos, bailes, procesiones y representaciones teatrales. ${ }^{1}$ Allí se escenificaba el poder, se habilitaba el ocio y también se producían desbordes. Tanto los bailes como los juegos propiciaron el encuentro de los diversos sectores sociales y aparecieron como algo transversal a todos los estamentos que componían a la sociedad. Los mismos integraban los procesos de legitimación y fortalecimiento del orden social, aunque no siempre aquel orden se presentase de manera unívoca. De hecho en muchos casos, los conflictos que se suscitaron en torno a las festividades, colaboraron en la resolución de interpretaciones y comunicaciones simbólicas entre las distintas visiones del mundo compartidas o no por los grupos e instituciones sociales más prominentes.

En la segunda mitad del siglo XVIII, muchos de estos eventos se independizaron de lo religioso. Juegos, bailes, toros y algunas formas del teatro fueron debatidos y disputados por distintos agentes del orden colonial. Ya fuera por ser espacios propicios para el desacato del orden social, por estimular los sentidos y las pasiones del cuerpo, por influenciar negativamente a los sectores acomodados, por limitar los tiempos religiosos o por hacer peligrar las economías domésticas. En ese periodo, funcionarios y pensadores ilustrados buscaron moderar el despliegue barroco, al mismo tiempo que ensayaron a partir de las festividades una serie de reformas culturales. En el plano local, gobernadores y capitulares prohibieron juegos y algunas expresiones musicales, aunque también promovieron otras. Se valoraba la eficacia moral de algunos eventos así como sus potencialidades económicas. El sector eclesiástico también tuvo voz en estos asuntos, entrando en colisión con algunos de los agentes del poder civil, tanto local como metropolitano, particularmente preocupado el divorcio que empezaba a producirse entre las festividades religiosas y las distintas expresiones del ocio social, como los toros, el teatro y las danzas. Asimismo la población mantuvo y desarrolló prácticas propias que no necesariamente se ciñeron a los límites de lo deseable y/o esperable por parte de las distintas autoridades.

En este contexto, los bailes festivos ocuparon un lugar como expresión festiva independientemente de las procesiones y celebraciones religiosas. El gobernador Vértiz organizó en Buenos Aires una serie de bailes de máscaras durante los carnavales de 1771 a 1773. Se proponía apropiarse de una serie de prácticas de los porteños y "reconducirlas" hacia formas culturales y sociales pasibles de organización y control. En paralelo se sucedieron otras expresiones de la danza y lo festivo que fueron también debatidas y alternativamente permitidas o prohibidas, como los denominados bailes de negros o tambos.

En este trabajo analizaremos el desarrollo de estas dos formas, prototípicas y antagónicas, de baile festivo. Para ello revisaremos las informaciones producidas a raíz de los bailes de máscaras llevados a cabo por iniciativa del gobernador Vértiz y por el otro una serie de debates capitulares respecto a lo que se consignó como los "bailes de negros" entre 1788 y 1789. A partir del examen de la documentación nos interesa reflexionar en torno a las formas en que se pretendió administrar el esparcimiento de la población, las distintas posiciones al respecto, así como las valoraciones esgrimidas en cada instancia. Entendemos la dificultad metodológica que encarna el análisis de documentación tan disímil. ${ }^{2}$ No obstante nos proponemos una mirada panorámica respecto a las valoraciones y los propósitos a partir de los cuales las elites gobernantes de la ciudad buscaron intervenir o incluso apropiarse de diversas formas festivas y expresiones populares de la sociedad porteña en el periodo tardo colonial. ${ }^{3}$

1 Diversas formas de diversión han sido parte de los intereses teóricos de disciplinas como la sociología y la antropología desde hace varias décadas. Se destacan los aportes de Elias y Dunning (1992) quienes señalan que tanto los juegos como los deportes permiten mitigar los estados de violencia propios de la naturaleza humana, dado que a través de su práctica los individuos pueden liberar una serie de emociones reprimidas, al tiempo que aprenden a sobrellevar situaciones complejas de sus vidas cotidianas. Los juegos y las fiestas, que como actividades de ocio permiten experimentar momentos de placer, de tensión y de emoción, tienen además un carácter liberador.

2 La primera representa una defensa ante el Consejo de Indias de un proyecto promovido por la gobernación de Buenos Aires y la otra una presentación del Procurador General de la ciudad ante el Cabildo denunciando los bailes de la población negra. Información sobre los bailes de máscaras, producida a raíz de los bailes de carnaval, 1773. AGN -A- Sala IX, hacienda, legajo 6, expediente 105, 32-8-5 // Acuerdos del Extinguido Cabildo de Buenos Aires (AECBA), AGN -A- 1933. Serie III, tomo XI, libros LIV - LV - LVI - LVII (1796-1800), Municipalidad de la ciudad de Buenos Aires, Buenos Aires.

3 Cabe señalar que, autores como Aguilar Vázquez (1972), Aguirre Beltran (2001), Bernand (2001), Chacon Zhapán (1990), Cicala (1994) y Coletti (1938), Jiménez Meneses (2012), Viqueira Alban (1987), entre otros, han descripto y analizado las diversas formas en que se expresaron los bailes en el siglo XVIII hispanoamericano y las percepciones que de ellos tuvieron funcionarios y miembros del clero. Asimismo, Acuña (1941), describe las partes de las diversas danzas vigentes en el periodo colonial y Vega (2014) reflexiona sobre el origen de las mismas en territorio americano. Para la ciudad de Buenos Aires se destacan los aportes de Barral (2007), Garavaglia (2007), Salas (2012), Lesser (2003) en torno al valor de las festividades como escenificación del poder y 
Respecto al contexto cabe señalar que en la segunda mitad del siglo XVIII y especialmente a partir de la década de 1760 en Hispanoamérica entraron en juego nuevas conceptualizaciones y prácticas en lo relativo a las formas y los propósitos de gobierno. Desde España, la dinastía borbónica pretendió sanear las finanzas, limitar las autonomías político-jurídicas desarrolladas en las colonias y contribuir en la conformación de economías más productivas. Entendiendo que los tres puntos mencionados se hallaban íntimamente relacionados e incluso determinados unos por otros, los pensadores ilustrados reflexionaron en torno a otros tipos de mecanismos que se volvían necesarios para la consecución de pueblos industriosos, felices y fiscalmente celosos.

Los sucesivos movimientos comprendidos en las reformas borbónicas buscaron por una parte, sistematizar los controles de la población, reorganizar los espacios y simplificar las vías de comunicación al mismo tiempo que pusieron el foco en mejorar la calidad de vida de la población. Para ello buscaron sanear los espacios urbanos, se propusieron construir paseos y espacios cerrados para el desarrollo de espectáculos como los toros o las funciones teatrales con el interés de organizar los tiempos y los comportamientos de los distintos estamentos que componían a las sociedades coloniales. Aquellas propuestas tuvieron como consecuencia una fuerte disputa por el espacio de urbano. Chocaron los ideales de control corporizados en los intentos por reformar calles, huecos y paseos, la realidad de una población que sistemáticamente ocupó los ámbitos compartidos de la ciudad y finalmente la parquedad de recursos disponibles para implementar tales reformas. ${ }^{4}$ En paralelo, las políticas borbónicas tendientes a restringir la autonomía de la iglesia marcaron, entre otras cosas, transformaciones en la forma y el contenido de los festejos urbanos. Para ciertos discursos el despliegue de lujo desatado en las fiestas aparecía ahora como un gasto innecesario. Los esfuerzos allí invertidos debían dedicarse al trabajo en tanto tarea productiva.

Ahora bien, las propuestas borbónicas debían redundar -idealmente- en una transformación, no solo de los aparatos de gobierno y justicia, sino también en los comportamientos, las prácticas y de algún modo las sensibilidades de la población en general y del bajo pueblo en particular. En qué medida el espíritu de las políticas culturales borbónicas fue exitoso en introducir formas de hacer y/o preferencias en las sociedades tardo-coloniales -particularmente la porteña-, es materia de discusión del presente trabajo. Consideramos que la variedad de reacciones que suscitaron las diversiones públicas representan un espacio privilegiado para analizar las prácticas, los hábitos y los comportamientos públicos de los diversos grupos sociales.

\section{El contexto de los bailes}

Las danzas, en tanto actividades que convocaban al ocio y al divertimento de la población, fueron una parte importante de la vida en las ciudades de Hispanoamérica. Los bailes se expresaron en diferentes formas, ritmos, espacios, así como también representaron -mayoritaria, pero no exclusivamente- a diversos públicos y fueron en distinta medida controversiales para algunos estamentos. Al respecto, Jiménez Meneses (2007) retoma una serie de preocupaciones esbozabas por el poder civil y eclesiástico neogranadino en torno a temas como, la convivencia étnica en los bailes, la mezcla de sexos, la asistencia a misa, la embriaguez, la relación con el tiempo de trabajo, entre otros. El autor demarca la existencia de dos mundos en lo referido a las danzas. Por una parte el ámbito de los bailes de salón, en tanto expresión de una elite que usaba de los ritmos cortesanos, la economía de movimientos y la moderación en el vestir. Por otra parte, el mundo de los fandangos, de los bailes nocturnos encarnados en "gente licenciosa y de poco lustre" (2007, p. 31). A cada ámbito correspondía, idealmente un sector social, aunque en la práctica las divisiones estamentales fueron habitualmente trasvasadas y tanto funcionarios como miembros de la elite participaron activamente de fandangos y bailes nocturnos. No obstante, el bajo pueblo en general y los negros libres y esclavos de las ciudades tuvieron vedado el acceso a los bailes de la elite. De hecho, la participación de los negros y mulatos en la cultura urbana inscribía mayormente al interior de la jerarquía estamental y era representada tradicionalmente en las festividades barrocas o, desde el siglo XVIII, en las conmemoraciones de la ciudad ilustrada. Desde el inicio del período colonial, las danzas de los negros acompañaron los cortejos religiosos y también la celebración de las fiestas reales (Bernand, 2001). Mientras que los indios se vestían con sus mejores trajes y ostentaban sus emblemas, los negros tocaban sus instrumentos musicales -flautas y tambores- distinguiéndose los grupos por sus ritmos específicos y su propio estilo. ${ }^{5}$ Más

las tensas relaciones que existieron entre funcionarios civiles y religiosos sobre actividades como los toros o el teatro en la ciudad. Respecto al cuerpo, el movimiento y la danza contamos con trabajos provenientes tanto de la antropología como de la historia de las sensibilidades, entre ellos, Citro 2009, Farge 2008, Le Breton 2002.

4 "El despotismo ilustrado no podía reformar la sociedad capitalina sin transformar a fondo sus calles, que eran su espacio fundamental. Es por esto que luchó para arrancarlas del pueblo, para acabar con el desorden que en ellas reinaba, y por volverlas agradables y acogedoras a la elite colonial" (Viqueira Alban, 1987,p. 138).

5 En las fiestas urbanas los cortejos de las cofradías negras entraban en exhibición junto a las otras corporaciones urbanas, cada una representada, cada una en su preciso lugar en la escenificación barroca. 
allá de aquella fiesta organizada y visibilizada en las procesiones, toda festividad tenía aspectos profanos y populares. Borracheras, juegos, excesos y movimientos sugerentes marcados por la música ejecutada por los negros, atraían y amenazaban de manera simultánea al orden y a la moral. ${ }^{6}$

Frente a esta realidad y comprendiendo la importancia de desarrollar y establecer, desde el gobierno, espacios en los que las formas de ocio y diversión cobrasen matices más "ordenados" y en ese sentido coadyuvasen a los planteos ilustrados, el gobernador Vértiz organizó entre 1771 y 1773 una serie de bailes de máscaras durante el periodo de carnaval. Retomando las palabras de Elías entendemos que estos proyectos "tuvieron por objetivo someter las espontaneidades y los desórdenes, asegurar una traducción adecuada y legible de la jerarquía de los estados, desarraigar las violencias que desgarraban el espacio social" (Elías, 1993, p. 259). En este contexto las fiestas y las celebraciones representaron al mismo tiempo, una suerte de "exaltación del instante" y una "función "pedagógica", en tanto arte de la persuasión por medio del despliegue de lo visual.

Garavaglia (2007 y 2002) y Lesser (2003) abordan el caso de las mascaradas en Buenos Aires y marcan un oportuno punto de comparación entre aquellos y los desarrollados en Madrid hacia 1767 a instancias del Conde de Aranda. En ambos casos se lee una búsqueda de parte de las autoridades por controlar y en cierta medida domesticar los festejos del carnaval. ${ }^{7}$ No obstante, en el caso porteño, los bailes fueron resistidos por parte del poder eclesiástico en la voz del franciscano Juan de Acosta. Aquel, tras amenazar con negar el sacramento a quienes participasen, inició un proceso que llegaría al Consejo de Indias y por el cual, dichos bailes serían finalmente prohibidos. En el pleito una veintena de testigos pertenecientes a la elite burocrática y militar porteña declararon favor de las mascaradas destacando diversas cuestiones y reseñando la forma en que los mismos fueron organizados por el gobierno de la ciudad. Años más tarde, miembros de la misma elite burocrática solicitarían al Cabildo la prohibición absoluta de los denominados "bailes de negros".

Nos interesa retomar los argumentos que se esgrimieron en ambos casos así como sus posibles resonancias respecto a las políticas ya mencionadas. Los bailes de máscaras, organizados por el gobernador, se planearon en parte como remedio y/o malla de contención respecto a los posibles desbordes que representaban otras expresiones festivas como los denominados bailes de los negros. En este sentido, dichos eventos representaron públicos, modos, comportamientos y espacios bien distintos y sin embargo en ambos casos encontraron resistencias, fueron contestados, debatidos y finalmente prohibidos.

\section{De juntas de negros y mascaradas}

Como ya fue mencionado, las diversas naciones africanas y sus danzas ocuparon un lugar importante en las festividades de la ciudad barroca, donde se buscaba subrayar las particularidades de cada uno de los estamentos. Sin embargo en la segunda mitad del siglo XVIII la corona buscó limitar el desarrollo de las celebraciones que escenificaban el orden social. La ostentación y la pompa desplegadas en dichos eventos se veían ahora como un freno a la modernización y una excusa para el vagabundeo. Para los criterios estéticos de la Ilustración, las danzas africanas resultaban excesivas, descarnadas e incluso bárbaras. ${ }^{8}$ No obstante, los llamados bailes de negros continuaron, estuvieran o no ligados a alguna de las celebraciones que ofrecía la ciudad. En el caso que aquí trataremos, referían a formaciones de las diversas naciones y/o cofradías porteñas. Los documentos hablan tanto de una serie de bailes organizados por aquellas como de la formación espontánea de estas rondas derivadas de otro tipo de "diversiones públicas" que tenían lugar en diferentes parajes, casas o huecos, mayormente en sitios ubicados extramuros ${ }^{9}$, donde el virrey había dado su permiso, aunque la documentación también menciona el paseo de la alameda como el espacio en que

6 Por otra parte, explica Jiménez Meneses (2012) que entre la población afro, no se establecían diferenciaciones rígidas entre las costumbres propias de la diversión y las del culto y usualmente los bailes eran parte de los rituales religiosos. Coincide Aguirre Beltran (2001) quien analiza el desarrollo de bailes de negros en el México colonial, el autor señala también como a pesar de las prohibiciones, las comunidades no dejaron de bailar, produciéndose una suerte de tira y afloje sistemático entre la prohibición y la permisividad.

7 No obstante, Carlos III acabó por prohibir los bailes de máscaras en las colonias sosteniendo que nunca había dado el permiso correspondiente para que se llevasen a cabo (Lesser, 2003, p. 120).

8 En este sentido, la visión Concolorcorvo sobre los bailes de los negros es sumamente gráfica; "Su canto es un aúllo. De ver sólo los instrumentos de su música se inferirá lo desagradable de su sonido. La quijada de un asno, bien descarnada, con su dentadura floja, son las curdas de su principal instrumento, que rascan con un hueso de carnero, asta u otro palo duro [...]. En lugar del agradable tamborilillo de los indios, usan los negros un tronco hueco, y a los dos extremos le ciñen un pellejo tosco. Este tambor le carga un negro, tendido sobre su cabeza, y otro va por detrás, con dos palitos en la mano, en figura de zancos, golpeando el cuero con sus puntas, sin orden, y sólo con el fin de hacer ruido [...] sus danzas se reducen a menear la barriga y las caderas con mucha deshonestidad, a que acompañan con gestos ridículos, y que traen a la imaginación la fiesta que hacen al diablo los brujos los sábados" ([1773] 1997, p.143).

9 La designación "extramuros" es recurrente en la documentación de Buenos Aires, aunque la ciudad no tuviera murallas físicas. En este sentido, designaba de manera relativamente variable los espacios que quedaban por fuera de la traza urbana. 
podían tener lugar. ${ }^{10}$ Se sobreentiende que estas formas de expresión corporal y social formaron parte de las prácticas habituales de la ciudad y que los representantes del gobierno urbano alternativamente dejaron pasar el fenómeno o lo atendieron en pos de lograr un cierto control del mismo, probablemente alertados por la magnitud de los mismos. Explicaba el procurador general, "Todos saben que lo menos se juntan dos mil negros, que estos unidos allí por cualquiera inquietud, quien será capaz de contenerlos, ni las desgracias, que podrán suceder" (AECBA, [1788] 1933, p. 629).

En cambio y como ya señalamos, las mascaradas surgieron directamente desde la esfera gubernamental, aunque atendiendo a las prácticas habituales en los carnavales porteños y en pos de conseguir unos festejos más ordenados en el espacio y el tiempo de la ciudad, "siendo esta diversión más honesta que los paseos que por el tiempo de carnaval hacían antes del establecimiento de las máscaras". Tal como advertía otro testigo dichos bailes respondían a "la necesidad de atraer a los pueblos en semejantes tiempos a una honesta y autorizada recreación para preservarlos de otras menos serias y recatadas", (Información sobre..., fs. 2 y 5 )

De acuerdo a la documentación, los mismos tuvieron lugar en "el casino público", también mencionado como la Ranchería, es decir en un espacio cerrado. ${ }^{11}$ Aquello respondía a los lineamientos borbónicos que buscaron evitar los comportamientos espontáneos de la multitud, reglamentarlos, constreñirlos a espacios cerrados y finalmente lograr administrarlos y por su intermedio administrar también los tiempos y las actividades de la población en la ciudad. Respecto al público que participaba de estos bailes, explica uno de los testigos, "que no se permitía entrada sino a españoles con el mas arreglado orden y honestidad", otro testigo señala que los mismos se daban con el "concurso de las principales familias de la ciudad" (Información sobre..., fs. 1 y 12).

Veremos ahora como retrataron los testigos de la época el comportamiento en ambos eventos, el despliegue de gustos de los asistentes y las consideraciones esbozadas respecto al rol que le correspondía al gobierno en la administración, el cuidado y el control de las expresiones festivas en la ciudad.

\section{Comportamientos, gustos, economía y educación}

Gracias a la información con la que contamos podemos tentar una reconstrucción sobre los modos y los comportamientos de los asistentes a los distintos eventos. Los testigos provistos por Vértiz en defensa de las mascaradas fueron recurrentes en señalar el buen cuidado de las formas y las conductas que allí observaron. Se trataba de una, "diversión honesta y decente". Don Juan Andrés de Arroyo, vecino y oficial de la Real Hacienda señalaba que, habiendo concurrido todos los años "se ha mantenido lo mas de la noche divertido con la variedad de trajes dando vueltas continuas y por todo el salón y nunca ha visto ni observado el menor desorden" (Información sobre..., f. 2). Otro testigo marcaba que: "no solo no notó en esta honesta diversión el más mínimo reprehensible exceso ni indicio de ofensa a dios nuestro señor, pero bien al contrario se maravilló el certificante al ver excedían el buen orden, prudente y cristiana providencias que en esta recreación se observaron" (Información sobre..., f. 7).

Las palabras clave que aparecen para referirse a los bailes tienen que ver con la armonía, la prudencia y la preservación de los valores "cristianos" y es esa la calidad que transmiten los testigos respecto al clima habitual en las funciones de máscaras. Asimismo, en la voz de los declarantes la templanza reseñada se combinaba con las afinidades y las inclinaciones de los porteños de quienes se destaca el gusto por la danza. ${ }^{12}$ Los testigos de la época entendían que las funciones propuestas por Vértiz eran las más "honestas" para los porteños quienes, "inclinados generalmente a los bailes halla ser lo más a propósito para que teniéndolos divertidos consiguientemente estén menos expuestos a inquietudes y desordenes que son comunes en los pueblos grandes en los días de carnaval" (Información sobre..., f. 11).

10 que en estos parajes, ni en casa y huecos (como suele acontecer) se ejerciten las referidas diversiones: acordaron que se pase dicha representación..." (AECBA, [1788] 1933, p. 626) y el testimonio del acuerdo al virrey para que él se sirva prohibir los mencionados bailes públicos y privados "(como siempre los ha prohibido Su Excelencia y para los cuales nunca quiso dar su permiso porque fueron de su total desagrado)" penas severas. En otro pasaje señala: "habiéndose hecho paseo y entretenimiento sin preveer estas malas consecuencias" (AECBA, [1788] 1933, p. 629).

11 Don Bartolomé Raimundo Muñoz interventor de la real renta de correos de la administración principal de esta ciudad y sus agregadas, que habiendo estado que en el casino público se celebraron en esta ciudad el próximo pasado carnaval observo el mejor orden sin que notase exceso ninguno (Información sobre..., f. 10).

12 Según una cura párroco portugués hacia 1778 en Buenos Aires era habitual que, por "las noches, principalmente las de invierno, las pasan la mayor parte en bailes particulares, ya con motivo de ser el santo del nombre de alguno de la casa, ya por ejercitarse en el arte de danzar, que todos poseen, aunque muy mal: y hay casas donde se reúnen todas las noches más de cuarenta personas para divertirse" (Pereira Fernández de Mesquita, [1778] 1980, p. 43). Asimismo, para 1808, el Virrey Cisneros señalaba que: "por cuanto también se ha notado la frecuencia con que en cualquier tiempo y por toda clase de gentes se hacen bailes, se prohíben estas diversiones no siendo en casas decentes y en circunstancias de festividades o regocijos, pero con la precisa calidad de que para hacerlas han de obtener primero los dueños de aquellas licencia por escrito de su respectivo alcalde de barrio..." (Citado en Tau Anzoátegui, 2004, p. 339). 
Se apelaba a la participación de los sectores más encumbrados de la sociedad con el propósito de que sus actitudes y movimientos fueran el modelo a seguir por parte del bajo pueblo. Una suerte de educación brotada del ejemplo. Las formas de la elite debían funcionar, al mismo tiempo como sanción y como expectativa ordenando así en ámbitos separados la conducta deseada y la indeseada en el contexto de la danza. Así lo explicaba un testigo: "que con su modo respetado de portarse no daban lugar a que algunos que no lo eran y que ningún hombre se propasase a alguna demostración reprehensible, embelesados todos en la música y variedad de disfraces" (Información sobre..., f. 12).

Otro punto que hacía también a la conducta estaba representado en el valor dado a la economía o mejor dicho a la conducta económica. El periodo borbónico estuvo signado por el cuestionamiento al gasto excesivo, en particular en las celebraciones cívico-religiosas propias del barroco. Por lo tanto, para los testigos que declararon a favor de las mascaradas era también relevante remarcar cierta idea del gasto cuidadoso como uno más de los aportes que dichas funciones realizaban al progreso de la sociedad porteña. Las diversiones no debían representar un desequilibrio respecto a la economía de los participantes y sus familias. Explicaba un testigo que la pasaba; "divertido con ver bailar a las gentes y con la variedad de los trajes que cada año se aumentaban por el poco costo que le hacían", y otro indicaba que los bailes no habían: "inferido al pueblo mayores gastos en los vestidos y disfraces pues han sido los más moderados" (Información sobre..., fs. 10 y 8$)$.

Cuál era el panorama de los bailes de los negros tal como están consignados por la documentación y de qué manera el Procurador General evaluaba el comportamiento de sus asistentes y los comunicaba al cuerpo capitular, estos bailes no son otra cosa que unos conventículos en que se renuevan en mucha parte los ritos de la gentilidad que visiblemente todos los gestos, demostraciones, los instrumentos de que se usa y aun las sonatas que tocan incitan eficazmente a la lujuria y con necesidad deben hacer impresión a la juventud (AECBA, [1788] 1933, p. 623).

Las juntas de negros o tambos fueron recurrentemente prohibidos por parte de gobernadores y virreyes por bandos de buen gobierno ${ }^{13}$, no obstante para el momento en que el Procurador General establece su petición, los mismos gozaban -tal como lo consigna la misma documentación- de algún tipo de permiso. Más allá de lo cual, el funcionario capitular estimaba que era preciso advertir a las autoridades que; "dedicados a estas diversiones ridículas en que renuevan las extravagancias de su país es imposible reducirles a la racionalidad y al ejercicio de la devoción, porque se arrastran con violencia a estas dichas diversiones" (AECBA, [1788] 1933, p. 624).

Se demarcaba la necesidad de construir unos parámetros precisos de comportamiento para esta población tan fácilmente impresionable y tan atada a la tradición irracional de la que provenían. Por otra parte, en este caso el ejemplo funcionaba de manera inversa al caso anterior, como posible corruptor de las conductas y no, como en el caso de las mascaradas como aleccionador, "de aquí también se sigue el escándalo y mal ejemplo que se da a todos los concurrentes, principalmente a las niñas y gentes inocentes porque abriendo los ojos y entrando la malicia en ellos, se anticipen a aprehender los que por modo alguno debían saber" (AECBA, [1788] 1933, p. 625).

Se mencionan las tradiciones, los gastos, las músicas y los movimientos. Las conductas son excesivas, obscenas, indecentes, se produce despilfarro y se alteran los espíritus. La permanencia de estas costumbres impide que las poblaciones de origen africano se desprendan de sus tradiciones "gentiles". ${ }^{14}$ La danza representa entonces un peligro, una posible forma de contagio de todas las prácticas indeseables y alejadas de la prudencia cristiana y la austeridad de movimientos: "los indecentes y obscenos movimientos que se ejecutan sin que de otro modo los puedan hacer, pues para ello contribuye el mismo son de sus instrumentos que es el mayor adictivo para alterar el espíritu haciendo concupiscible y poniendo en movimiento y disposición de practicar las mismas obscenidades" (AECBA [1788], 1933, p. 626).

Los bailes mantienen a sus concurrentes apegados a la irracionalidad de sus costumbres e impiden que la devoción permee sus comportamientos, se habla de la "ruina de las almas" y de "las muchas y graves ofensas que hacen a dios". Contraria a la exaltación respecto a la economía de los trajes durante las mascaradas, se denunciaba aquí el recurso a gastos extraordinarios "que deben con precisión deducir del robo y rapiña" (AECBA, [1788] 1933, p.623). El funcionario va más allá y denuncia que durante los bailes "sacan

13 Contamos con tres Bandos de Buen Gobierno en que se prohíben los bailes de negros. En 1766 y 1770, corresponden a los gobernadores Bucareli y Vértiz respectivamente y el tercero en 1790 firmado por el Virrey Arredondo, en el que decía: "prohíbo los bailes que con el nombre de tambo usan los negros, en que se relajan y distraen del servicio de sus amos para entregarse a una diversión que envuelve acciones y movimientos indecentes y cantares obscenos, con gravamen de las conciencias de unos y de otros" (Citado en Tau Anzoátegui, 2004, p. 309).

14 En el documento se señala que, "no son de menos peso lo que en estos mismos bailes hacen los negros, como ya se ha observado, que ha sido el hacer recibir los ritos de la gentilidad en que nacieron con ciertas ceremonias y declamaciones que hacen en su idioma" (AECBA, [1788] 1933, p. 628). 
allí cierta contribución que con capa de obra pía” (AECBA, [1788] 1933, p. 628) que luego invertían en comprar la libertad de algunos, entendía el Procurador que esto solo era posible robando a sus amos y faltando también a sus obligaciones respecto a la iglesia: "no piensan en otra cosa, sino en la hora de ir a bailar, pero lo más notable de todo es lo que ejecutan en los días de ambos preceptos que los deben dedicar a dios y santificar sus fiestas; pues aun en estas mismas diversiones mezclan un trabajo corporal con la violencia de ellas" (AECBA, [1788] 1933, p. 629). ${ }^{15}$

En la cita, aparece referido por un lado lo corporal, lo excesivo y por el otro, la consideración respecto a la obligación frente a los amos, los jueces, la iglesia. De hecho, en el texto de la denuncia se entrelaza el trabajo como contraparte de la vagancia y el desorden, la falta a la moderación cristiana al despilfarro y finalmente a la violencia. Tópicos habituales del siglo XVIII, aparecen aquí ligados directamente a formas festivas, se está hablando del rol que las diversiones públicas tienen dentro del esquema de gobierno, ya sea para construir mandatos como para rechazarlos. En ambos casos los miembros de la elite porteña que se expresan a favor de las mascaradas y en contra de los bailes de los negros, se refieren al rol que debe jugar el gobierno en tanto autoridad rectora respecto a las diversiones públicas y sus posibles derivaciones.

\section{Gobierno y recreación}

Los testigos que hablaron a favor de los bailes de máscaras fueron recurrentes en señalar los diversos modos en que los encargados del gobierno de la ciudad buscaron mantener un correcto orden, un cierto gobierno del ocio que sirviera para "asegurar una honesta y recatada recreación y evitar las ofensas de dios nuestro señor" (Información sobre..., f. 1). Veremos, a partir de los testimonios, cuáles fueron los medios empleados para lograrlo.

Señalan los testigos que el gobernador había cuidado el desarrollo de las funciones desde la entrada misma de la Ranchería. Allí, se fijaba un cartel en el que quedaban señalados los preceptos a cumplir por parte de los asistentes. ${ }^{16}$ Las patrullas de caballería debían permanecer en las calles y se indicaba que en las "bocas inmediatas al casino no se permitiese gentes paradas porque no hubiese confusión entre uno y otro sexo". A su vez, los jueces de primer y segundo voto, los jueces comisionados y el teniente del rey presenciaban las funciones. Asimismo, el gobernador había dispuesto "centinelas en todas las habitaciones" y los testigos consignan la presencia de los alcaldes, el alguacil mayor, los cabos militares, "que los ha visto practicar con la mayor decencia y con las exactas y celosas precauciones del gobierno" hasta finalizada la función (Información sobre..., fs. 1 y 5 ). ${ }^{17}$

En este sentido, una clave para mantener el orden y las buenas conductas, radicaba en la organización del espacio y en el cuidado puesto en el armado del ámbito destinado a los bailes, "no era creíble que en una sala tan bien dispuesta sin más piso que el de su suelo y el de la gradería corrida a las paredes, con una iluminación superabundante pudiese haber exceso sin que fuese notorio a todos" (Información sobre..., f. 10). Esta declaración encarna en la propia esencia de las mascaradas como proyecto de gobierno. Un espacio cubierto, iluminado y controlado en el cual cualquier forma de agravio fuese visiblemente censurable no solamente por la tropa, sino por todos los asistentes. Nuevamente aparece una cierta idea de disciplina por contacto y/o imitación, tanto en las conductas a adquirir como en aquellas que se debían rechazar. Pero no todo el evento se daba en el espacio cubierto del salón. La ranchería tenía un patio trasero en el cual los comportamientos de los asistentes debían ser considerados con la misma disciplina que al interior, especialmente en lo que refería a las relaciones entre hombres y mujeres. Allí, la tropa mantenía el cuidado necesario para "no permitir conversaciones en el patio del casino en donde refrescaban las gentes y que en caso de convidar los hombres a las mujeres, estas estuviesen sentadas en sus bancos y los hombres las sirviesen en pie sin permitirles sentarse, estando todo iluminado" (Información sobre..., f. 6). Se buscaba que nada quedase oculto, la exposición, el ejemplo y la presión de la tropa constituían el ambiente en el cual -según los testigos- se desplegaron las mascaradas.

15 “...en el incesante de los instrumentos que tocan y la fuerza con que los hacen levantar de punto al compás de sus lascivas canciones, como en la que igualmente ponen en las diferentes danzas con que cada nación se diferencia, pudiéndose con verdad decir que en estos bailes olvidan los sentimientos de la santa religión católica, que profesaron, renuevan los ritos de su gentilidad, se pervierten las buenas costumbres, que les han enseñado sus amos no aprehenden sino vicios y se hacen por todos modos perjudiciales" (AECBA, [1788] 1933, p. 629).

16 Mucha puntualidad en cumplir los preceptos que se impusieron por cartel fijado en la puerta de la entrada con lo cual y con presenciar los bailes la justicia ordinaria y comisionados celadores a más del respeto del Gobernador y Capitán General, el del Teniente del Rey y otros individuos de distinción que asistían. (Información sobre..., f. 10).

17 Otro testimonio indica; “... estaban nombrados por orden del Gobernador y Capitán General una guardia de un oficial, un sargento, un cabo y veinte cuatro granaderos, asistiendo el mismo superior Teniente de Rey y auditor de guerra, los dos alcaldes ordinarios y alguacil mayor de esta plaza y el que certifica que ejerce las funciones de sargento mayor de ella todos con la orden del señor gobernador y capitán general" (Información sobre..., f. 6). 
Contrario a las precauciones tomadas en las mascaradas, durante los tambos la congregación masiva de gente y la ausencia de control de parte de los miembros del gobierno producía; "estragos y tumultos difíciles de precaver entre esta clase de gentes sin cultura y de genio obstinado en sus empresas" (AECBA, [1788] 1933, p. 623). Se denunciaba la "insolencia", la "mucha libertad" y los excesos cometidos en el trato a la "gente blanca". ${ }^{18}$ Esta exhortación puede ser leída en dos escalas. Por una lado abre la pregunta respecto a la presencia de gentes "condecoradas y distinguidas por su calidad y estado" (AECBA, [1788] 1933, p. 627) en los mencionados bailes de los negros y si los tratos indebidos que se señalan sucedían efectivamente durante los tambos. La otra mirada posible al respecto en la que plantea los peligros de las danzas y de la experiencia en relación a los comportamientos de sus asistentes por fuera del evento, una suerte de contagio inverso al buscado con las mascaradas. Circula en el texto la idea de que hay una serie de conductas excesivas que se recrudecen en las danzas y se cimentan en el ethos de la población negra en la ciudad. Frente a ello, "y a lo mucho que importa tener a esta clase de gentes con sumisión y una subordinación que les haga comprehender lo justa de ella", correspondía al gobierno y justicia de la ciudad, los contenga y reduzca a los límites de su obligación con propio conocimiento de su bajeza y del modo con que se deben comportar con todos, sin excederse, ni propasarse a ningún exceso que de motivo a queja alguna, pues de esta suerte se lograra el que vivan con más subordinación (AECBA, [1788] 1933, p. 626-627).

Los eventos generaban un tipo de corrupción que resultaba en "un perjuicio muy sensible e irreparable el estado y el público", estos se debía las costumbres gentiles que se revistaban en los bailes y a las cuales se les adjudicaban "los muchos desordenes que se experimentan". La inquietud se asentaba en el "crecido el número de los negros que hay en esta ciudad", frente al cual urgía, "una grande atención y cuidado con ellos, celando su conducta, no perderlos jamás de vista y ni tampoco dispensarles ningún exceso, pues por su carácter inclinados y propensos a todo lo malo, se debe vivir con ellos con la mayor desconfianza" (AECBA, [1788] 1933, pp. 627, 628 y 630).

Se establecía así la prohibición de los bailes y una advertencia respecto a las juntas de negros por motivos religiosos. En caso de que fueran ineludibles, debían hacerse con asistencia de un juez real y el "auxilio necesario de la tropa" que servirán para contener, "una desgracia o un tumulto, que por falta de ella pueda suceder". Se buscaba contener, cercar y circunscribir esta forma de diversión, al punto de lograr ya fuera su erradicación, ya fuera su domesticación. Se denunciaba el peligro, y la "gran consternación" que las juntas de los negros representaban para toda la ciudad y se establecía una intervención gubernamental concreta sobre las formas populares de recreación social, de modo que para estas juntas, concursos y las que se trata de diversiones públicas no se pueden hacer sin noticia y permiso del jefe principal, a fin de que precaviendo con sus providencias los desórdenes que pueden sobrevenir provea con tiempo el remedio (AECBA, [1788] 1933, pp. 630 y 631).

\section{Reflexiones finales}

Al referirse a los cuerpos de las poblaciones pobres en el París del siglo XVIII, Arlette Farge explica; "como viven afuera y conocen entre si una gran promiscuidad, sus maneras de ser, sus gritos, sus formas de ser en grupo, su vivacidad o sus indignaciones, lágrimas o efusiones manifiestan una corporeidad y una verdadera sensualidad también observadas y temidas, por las autoridades" (2008, p. 16) y más adelante remarca; "la multitud, sinónimo de contacto inquietante, superaría el frágil umbral de los roces entre los cuerpos, entre la pasión embriagada y el desapego necesario" (2008, p. 166).

En este trabajo abrimos una serie de preguntas en torno a la relación entre bailes festivos, intervención/ acción gubernamental, control y/o desborde en el periodo signado por el reformismo borbónico en la ciudad de Buenos Aires. Es decir, al interior de una sociedad fronteriza, en la que los límites socio estamentales no adquirieron -pese a la elevación virreinal- el peso que tuvieron en ciudades como Lima o México. En este sentido abrimos una indagación comparada entre dos formas de bailes o festividad que se sucedieron y que provocaron reacciones particulares. Los documentos con los que contamos -ya sean en su defensa como en su condena en cada caso-, nos permiten plantear una serie de elementos a partir de los cuales las autoridades evaluaron la multitud, el contacto, la moderación o el exceso. Tal como explica Carmen Bernand (2001, p. 161) en el siglo XVIII y bajo la influencia del pensamiento ilustrado se fue acentuando una cierta manera de distinguir entre las danzas. Por un lado, autoridades y pensadores borbónicos valoraban aquellas de movimientos moderados que solo involucrasen a los pies. Por el otro, proliferó un heterogéneo conjunto de los bailes del bajo pueblo en los que se manifestaban gestos de mayor libertan en brazos y pies. En todas las

18 "el mucho desorden y exceso que se notaba en la mucha libertad e insolencia con que toda la negrada y mulatería trataba a toda la gente blanca, propasándose con un exceso que jamás se ha visto, de faltar el respeto y veneración debida a todas las gentes y principalmente todas aquellas condecoradas y distinguidas por su calidad y estado" (AECBA, [1788] 1933, p. 622). 
ciudades, fandangos, tambos, bundes, o candombes llamaron la atención y atrajeron a personas de las más variadas extracciones sociales.

Frente a este panorama, aprovechando el gusto de los porteños por las festividades y las danzas y a tono con los propósitos borbónicos tendientes a proponer formas de ocio que pudieran ser fácilmente controlables es que se propusieron los bailes de máscaras. El evento era organizado e intervenido por el poder gubernamental en base a dos ejes centrales. Por una parte que los tiempos de relegación resultaban potencialmente peligrosos al orden, o a la pretensión de orden social vigente, y por otra parte que esa misma potencialidad podía redireccionarse en función de una agenda gubernamental específica que, contemplando la estratificación social vigente propusiese un modelo de conducta a seguir, sin por eso abandonar el aspecto lúdico del ocio y el rol que se le asignaba respecto al descanso de jornaleros y artesanos. Asir el desborde carnavalesco, a la multitud y a sus efusiones. Crear un modelo de conducta apto y otro censurable y practicar el ejemplo. No obstante, las políticas culturales borbónicas se vieron severamente contestadas, ya fuera por el poder eclesiástico como por las propias lógicas sociales que atravesaban a los porteños en sus gustos, prácticas, deseos y necesidades, cualquiera fuera el sector socio estamental al que pertenecieran. En este sentido, la pretensión por modelizar la experiencia de ocio quedó restringida por las encrucijadas propias, de la política, la sociedad y la experiencia del periodo tardo colonial hispanoamericano.

\section{Fuentes}

Acuerdos del Extinguido Cabildo de Buenos Aires (AECBA), AGN -A- 1933. Serie III, tomo XI, libros LIV - LV - LVI - LVII (1796-1800), Buenos Aires, Municipalidad de la ciudad de Buenos Aires.

Concolorcorvo ([1773] 1997). El Lazarillo de ciegos caminantes. Buenos Aires, Emecé.

Información sobre los bailes de máscaras, producida a raíz de los bailes de carnaval, 1773. AGN -A- Sala IX, hacienda, legajo 6, expediente 105, 32-8-5.

Pereira Fernández de Mesquita, Pedro ([1778] 1980). Relación de la conquista de Colonia por D. Pedro de Cevallos y descripción de la ciudad de Buenos Aires. Traducción, prólogo y notas: Fernando O. Assunçao. Buenos Aires, Academia Nacional de la Historia.

\section{Bibliografía}

Acuña, A. (1941). Los bailes coloniales. Anales de la Universidad de Chile, n. 44, pp. 163-173. Recuperado: http://www.anales.uchile.cl/index.php/ANUC/article/view/24529/25884 Fecha de acceso: $17 / 07 / 2017$

Aguilar Vázquez, C. (1972). Obras completas. Quito, Ecuador: Editorial Fray Jodoco Ricke.

Aguirre Beltrán, G. (2001). Bailes de negros. Desacatos, Centro de Investigaciones y Estudios Superiores en Antropología Social Distrito Federal, vol. 007, pp. 151-156.

Bernand, C. (2001). Negros esclavos y libres en las ciudades hispanoamericanas. Madrid, España: Fundación histórica Tavera.

Barral, M. E. (2007). Lo religioso como dimensión de análisis en la historiografía social sobre Hispanoamérica en el período colonial, Sociedad y Religión: Sociología, Antropología e Historia de la Religión en el Cono Sur, vol. XVIII, (núm. 28-29), pp. 87-101.

Chacón Zhapán, J. (1990). Historia del corregimiento de Cuenca (1557 - 1777), Quito, Ecuador: Banco Central del Ecuador.

Cicala, M. (1994). Descripción histórico-topográfica de la provincia de Quito de la Compañía de Jesús. Quito, Ecuador: Biblioteca Ecuatoriana Aurelio Espinosa Pólit.

Citro, S. (2009). Cuerpos Significantes. Travesías de una etnografía dialéctica. Buenos Aires, Argentina: Biblos.

Elías N. y Dunning E. (1992). Deporte y Ocio en el Proceso de la Civilización, Madrid, España: Fondo de Cultura Económica.

Elías, N. (1993). El proceso de la civilización. Investigaciones sociogenéticas y psicogenéticas, Buenos Aires, Argentina: Fondo de Cultura Económica.

Farge, A. (2008). Efusión y tormento. El relato de los cuerpos historia del pueblo en el siglo XVIII. Buenos Aires, Argentina: Katz.

Garavaglia, J. C. (2000). "A la nación por la fiesta": las Fiestas Mayas en el origen de la nación en el Plata", Boletín del Instituto de Historia Argentina y Americana Dr. Emilio Ravignani, № 22, pp. 73-100. 
Garavaglia, J. C. (2007). Construir el estado, inventar la nación: El Rio de la Plata, siglos XVIII-XIX, Buenos Aires, Argentina: Prometeo.

Jiménez Meneses, O. (2012). Los rostros de la Memoria afrodescendiente: fiestas, bailes y fandangos. Universidad Nacional de Colombia. Recuperado: http://www.bdigital.unal.edu.co/1237/20/19CAPI18. pdf Consultado el 13-07-2017

Jiménez Meneses, O. (2007). El frenesí del vulgo. Fiestas, juegos y bailes en la sociedad colonial. Medellín, Colombia: Universidad de Antioquia.

Le Breton, D. (2002). Antropología del cuerpo y modernidad. Buenos Aires, Argentina: Nueva Visión.

Lesser, R. (2003). Los orígenes de la Argentina. Historias del reino del Rio de la Plata, Buenos Aires, Argentina: Biblos.

Salas, A. M. (2012). Rigor religioso versus fervor popular toros en Buenos Aires, 1780-1782. Revista de Estudios Taurinos N. ${ }^{\circ} 31$, pp. 133-151.

Tau Anzoategui, V. (2004). Los bandos de buen gobierno del Río de la Plata, Tucumán y Cuyo (época hispánica). Buenos Aires, Argentina: Instituto de Historia del Derecho.

Vega, C. 2014. "Acerca del origen de las danzas folklóricas argentinas" [en línea]. Revista del Instituto de Investigación Musicológica "Carlos Vega”, Recuperado:

http://bibliotecadigital.uca.edu.ar/repositorio/revistas/acerca-origen-danzas-folkloricas.pdf Consultado el 08-07-2017.

Viqueira Albán, J. P. (1987). ¿Relajados o reprimidos? Diversiones publicas y vida social en la ciudad de Adexico durante el Siglo de las Luces, DF. México: FCE. 